\title{
INHALTSVERZEICHNIS
}

\section{S. KrAMER}

Der Einfluß der Bodenbearbeitung und des Unkrautbekämpfungsmittels W 6658

bei Erdbeeren . . . . . . . . . . . . . . . . . . . . . . . . . . . . . 299

R. BeNne, und G. WiTtia

Untersuchungen über den Einfluß differenzierter Stickstoffgaben auf Wuchs und

Ertrag von Roten Johannisbeeren … . . . . . . . . . . . . . 313

G. WINKLER

Untersuchungen über den Einfluß von Wuchsstoffen auf den Knollenertrag bei

Gladiolen . . . . . . . . . . . . . . . . . . . . . . . . . 325

R. WEICHOLD und G. VOGEL

Untersuchungen zur Ertragsleistung beim Anbau von Stutztomate in Abhängigkeit von der Standweite, der Anzahl von Blütenständen und vom Pflanztermin zur

Nutzungsfolgegestaltung in Gewächshäusern aus Plastwerkstoffen . . . . . . . 341 